Conclusion: While the pharmacy cost was higher for abatacept compared to adalimumab driven by the rebate, due to its higher clinical efficacy, the CPR was consistently lower for SE+ RA patients treated with abatacept. The results may be useful for US healthcare decision makers in understanding how to optimize treatment for SE+ RA patient while minimizing costs in today's budget constrained environment.

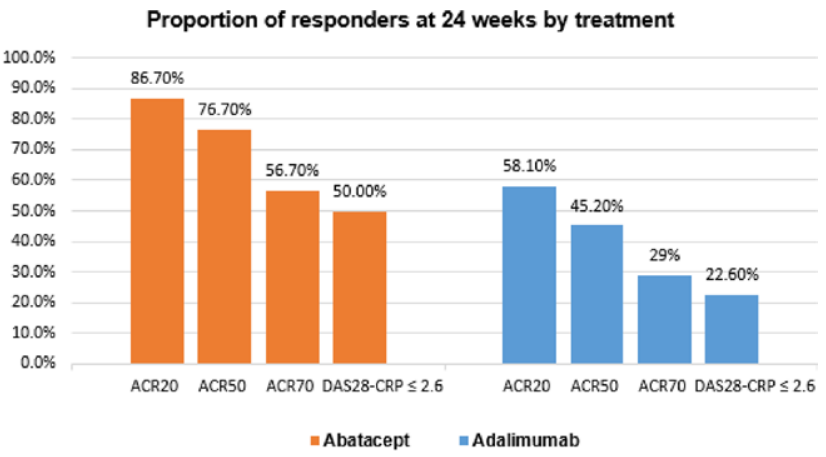

Figure 1. Proportion of responders by treatment data from the Early AMPLE trial

References:

[1] Gregersen PK, Silver J, Winchester RJ. The shared epitope hypothesis. An approach to understanding the molecular genetics of susceptibility to rheumatoid arthritis. Arthritis and rheumatism. 1987;30(11):1205-13.

[2] Holoshitz J. The rheumatoid arthritis HLA-DRB1 shared epitope. Curr Opin Rheumatol. 2010;22(3):293-8.

[3] Sakkas LI, Bogdanos DP, Katsiari C, et al. Anti-citrullinated peptides as autoantigens in rheumatoid arthritis-relevance to treatment. Autoimmun Rev. 2014;13(11):1114-20.

[4] Fleischmann R, Weinblatt M, Ahmad H, et al. Efficacy of abatacept and adalimumab in patientsn with early rheumatoid arthritis with multiple poor prognostic factors: post hoc analysis of a randomized controlled clinical trial (AMPLE). Rheumatol Ther. 2019;6(4): 559-571.

[5] Truven Health Analytics. Redbook online. Accessed October 11, 2019

Disclosure of Interests: Sang Hee Park Consultant of: Pharmerit International, which received consultancy fees from Bristol-Myers Squibb (US), Inc. for this study, Xue Han Employee of: BMS, Francis Lobo Shareholder of: Bristol-Myers Squibb (US), Employee of: Bristol-Myers Squibb (US), Sakina Nanji Consultant of: Pharmerit International, which received consultancy fees from Bristol-Myers Squibb (US), Inc. for this study, Dipen Patel Consultant of: Pharmerit International, which received consultancy fees from Bristol-Myers Squibb (US), Inc. for this study

DOI: 10.1136/annrheumdis-2020-eular.1019

\section{AB1165 MEDICATION ADHERENCE DATA IN A RANDOMIZED TRIAL: LARGE CHALLENGES TO COME FROM RAW DATA TO A WORKABLE AND RELIABLE DATASET}

L. Hartman $^{1,2}$, E. Alessandri ${ }^{3}$, R. Bos ${ }^{4}$, D. Opris-Belinski ${ }^{5}$, M. R. Kok ${ }^{6}$, H. GriepWentink $^{7}$, R. Klaasen ${ }^{8}$, C. Allaart ${ }^{9}$, G. Bruyn ${ }^{10}$, H. Raterman ${ }^{11}$, M. Voshaar ${ }^{12}$, N. Gomes ${ }^{13}$, R. Pinto ${ }^{14}$, T. Klausch ${ }^{2}$, W. Lems ${ }^{1}$, M. Boers ${ }^{1,2}$. ${ }^{1}$ Amsterdam Rheumatology and Immunology Center, location VUmc, Amsterdam, Netherlands; ${ }^{2}$ Amsterdam UMC, location VUmc, Epidemiology \& Biostatistics, Amsterdam, Netherlands; ${ }^{3}$ University of Genoa, Genoa, Italy; ${ }^{4}$ Medical Center Leeuwarden, Leeuwarden, Netherlands; ${ }^{5}$ University of Medicine and Pharmacy 'Carol Davila", Bucharest, Romania; ${ }^{6}$ Maasstad Hospital, Rotterdam, Netherlands; ${ }^{7}$ Antonius Ziekenhuis, Sneek, Netherlands; ${ }^{8}$ Meander Medical Center, Amersfoort, Netherlands; ${ }^{9}$ LUMC, Leiden, Netherlands; ${ }^{10}$ MC Groep, Lelystad, Netherlands; ${ }^{11}$ Noordwest Ziekenhuisgroep, Alkmaar, Netherlands; ${ }^{12}$ Tools, Amsterdam, Netherlands; ${ }^{13}$ Exatronic, Aveiro, Portugal; ${ }^{14}$ Bluepharma, Coimbra, Portugal

Background: Medication adherence in the GLORIA trial, among elderly patients with rheumatoid arthritis, is measured with caps that register openings of the medication bottle. At each study visit, one or two medication bottles with cap (kits) are dispensed, each containing 90 capsules. Multiple steps are needed to come to a workable dataset to describe adherence.

Objectives: To describe the steps that are needed to come from raw data to a workable dataset to analyze adherence data that are recorded by electronic caps.

Methods: The medication bottle contains a cap with the ability to register cap openings. The raw dataset from the caps consist of an excel file with one opening event per row, recorded as date and time. One cap yields approximately 90 rows. First, the kit numbers were matched to the corresponding patient numbers, that are recorded in another excel file. Instances where two kits were dispensed were recorded with two kit numbers in one cell and need to be copied to two cells with one kit number. Second, the VLOOKUP function was used to combine dates and kit numbers. One row now contains all openings from one kit. Then, the number of days between first opening and each next opening date was calculated. A range of 90 days was made to calculate how many times the bottle was opened on each day of the 90-days period. The results were color-coded to visualize instances of zero, one or $\geq$ two openings on a day.

Results: The colored calendar matrix (Figure 1) can now be used to categorize adherence patterns.

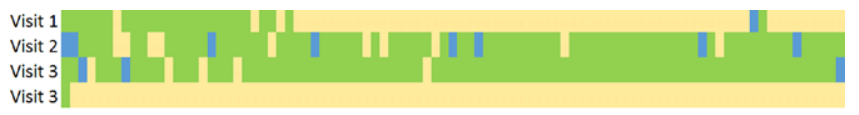

Figure 1. Example of calendar matrix of four caps of one patient.

Yellow=no opening, green=1 opening, blue=22 openings.

Conclusion: A monitoring cap seems a simple instrument to measure adherence. However, multiple steps and a lot of time are needed to come to a workable dataset for the study of adherence patterns.

Acknowledgments: The GLORIA project is funded by the European Union's Horizon 2020 research and innovation programme under the topic "Personalizing Health and Care", grant agreement No 634886.

Disclosure of Interests: Linda Hartman: None declared, Elisa Alessandri None declared, Reinhard Bos: None declared, Daniela Opris-Belinski Speakers bureau: as declared, Marc R Kok Grant/research support from: BMS and Novartis, Consultant of: Novartis and Galapagos, Hanneke Griep-Wentink: None declared, Ruth Klaasen: None declared, Cornelia Allaart: None declared, George Bruyn: None declared, Hennie Raterman Grant/research support from: UCB, Consultant of: Abbvie, Amgen, Bristol-Myers Sqibb, Cellgene and Sanof Genzyme, Marieke Voshaar Grant/research support from: part of phd research, Speakers bureau: conducting a workshop (Pfizer), Nuno Gomes: None declared Rui Pinto: None declared, Thomas Klausch: None declared, WIllem Lems Grant/ research support from: Pfizer, Consultant of: Lilly, Pfizer, Maarten Boers: None declared

DOI: 10.1136/annrheumdis-2020-eular.3638

\begin{tabular}{|l|l|}
\hline AB1166 & DETERMINANTS OF REPOSITORY CORTICOTROPIN \\
INJECTION TREATMENT INITIATION FOR PATIENTS \\
WITH RHEUMATOID ARTHRITIS IN A LARGE CLAIMS \\
DATABASE
\end{tabular}

K. Hayes ${ }^{1}$, M. Panaccio ${ }^{2}$, H. Zhou ${ }^{3}$, M. Fahim ${ }^{3} .{ }^{1}$ Mallinckrodt Pharmaceuticals, Hazelwood, MO, United States of America; ${ }^{2}$ Mallinckrodt Pharmaceuticals, Bedminster, NJ, United States of America; ${ }^{3}$ KMK Consulting Inc, Morristown, NJ, United States of America

Background: The treatment goal in rheumatoid arthritis (RA) is sustained remission and prevention of RA flares [1]. While targeted biologics have improved disease outcomes, almost one-third of patients (pts) discontinue treatment by 1 year and $50 \%$ by 2 years, with lack of efficacy as the most common reason [2] Repository corticotropin injection $(\mathrm{RCl})$ is a naturally sourced complex mixture of adrenocorticotropic hormone analogues and other pituitary peptides and is an agonist for all 5 melanocortin receptors (MCRs). Activation of MCRs by $\mathrm{RCl}$ has been shown to have direct and indirect anti-inflammatory and immunomodulatory effects. $\mathrm{RCl}$ is indicated for adjunctive therapy for short-term administration in RA flares or uncontrolled disease [3]

Objectives: To characterize RA pts that initiate $\mathrm{RCl}$ therapy and identify predictors of $\mathrm{RCl}$ initiation, compared to biologic disease-modifying antirheumatic drugs (DMARDs).

Methods: This retrospective cohort study identified pts with ICD-9/10 diagnosis for RA over an 11-year period (2008-2018) in a large claims database (Truven MarketScan $\AA$ ). Adults with $\geq 1$ claim for $\mathrm{RCl}$ ( $\mathrm{RCl}$ cohort) or $\geq 1$ RA-related biologic claim but no $\mathrm{RCl}$ (non- $\mathrm{RCl}$ cohort) were selected and characterized by demographics, disease severity (Claims-based Index for RA Severity, CIRAS), comorbidities (Charlson Comorbidity Index, CCI), treatment patterns, and healthcare resource utilization in the 12-month baseline $(\mathrm{BL})$ period prior to their index date (i.e., the $1^{\text {st }} \mathrm{RCl}$ claim or last claim for biologic for non- $\mathrm{RCl}$ cohort). Predictors of $\mathrm{RCl}$ initiation were identified by multivariable logistic regression, controlling for demographics and BL characteristics.

Results: A total of 393 pts initiated $\mathrm{RCI}$ therapy while 188,062 initiated biologic treatment with no $\mathrm{RCl}$ claims. At $\mathrm{BL}$, cohorts were similar with respect to mean age ( 56 years), gender (76-79\% female), and insurance type (79-80\% commercial). Cohorts differed by region, plan type, and index year. Compared to non- $\mathrm{RCl}$ 